\title{
A DIgNIdAde da CIÊnCIA POLÍTICA E AS INTERPRETAÇÕES DO BRASIL
}

LINHAGENS DO PENSAMENTO POLITICO BRASILEIRO,

de Gildo Marçal Brandão. São Paulo: Hucitec, 2007.

LUIZ EDUARDO SOARES

Linhagens do pensamento politico brasileiro é uma obra ímpar, destinada a figurar em todas as bibliotecas e bibliografias sérias de ciência política, história, sociologia e filosofia política, marcando, definitivamente, o ingresso de seu autor, Gildo Marçal Brandão, no cânone brasileiro das ciências humanas. Trata-se de um trabalho verdadeiramente extraordinário, que só a maturidade autoriza. Não me refiro apenas à maturidade intelectual, que tempera o espírito, promovendo o encontro raro entre a erudição e o refinamento seletivo dos critérios, encontro que potencializa as virtudes do pensador quando se associa à habilidade para mobilizar vastos recursos heterogêneos com precisão de artilheiro e delicadeza de ourives. Evoco também, nessa equação, a maturidade política e existencial, que reina, aqui, sob o signo da fidalguia e da generosidade - essas qualidades, afinal, não podem estar alheias ao reiterado reconhecimento do valor de posições e concepções radicalmente opostas àquelas a partir das

[1] Essas posturas poderiam ser lidas como sinais de um pluralismo não-relativista, que tanto agradaria a um liberal de primeira grandeza, Isaiah Berlin, cujos méritos talvez merecessem mais atenção do autor. quais o autor pensa e atua. ${ }^{1}$

Desembaraçado de artificialismos retóricos e jargões disciplinares, geralmente fruto da insegurança de seus autores e da debilidade de seus argumentos, o texto - enxuto, agudo, justo, severo, rigoroso, mas em tudo saboroso, primoroso - flui, encanta e persuade, sem que elegância e paixão se anulem, mutuamente, ou se excluam. Eis aí, o autor e sua obra, virtude espelhando talento, consagrando uma vocação.

O núcleo do projeto intelectual que a obra realiza é indissociável da dimensão política que sua inscrição histórico-institucional comporta e dificilmente se afirmaria sem que determinadas condições éticas - e até mesmo existenciais, ousaria dizer - fossem atendidas (uma das quais já foi mencionada). Seria razoável descrever o núcleo 
nos seguintes termos:é possível apreender - o autor nos diz como e por quê, aplicando essa abordagem e gerando resultados analíticos - os pontos em que se cruzam (e a partir dos quais se constituem) as linhas de força do pensamento político brasileiro e os processos reais por aquele interpelados, provocados ou mesmo dirigidos. De tal maneira que o quadro hermenêutico (envolvendo inevitável taxonomia) não se esgota na identificação dos paradigmas ${ }^{2}$ do pensamento político brasileiro, os quais qualificam, limitam e distinguem seu movimento heurístico. Vai além, estendendo seu espectro de abrangência à experiência vivida da política, sobretudo nos momentos de crise, em que os paradigmas revelam suas potencialidades cognitivonorteadoras, assim como explicitam suas fragilidades e exibem suas áreas de sombra.

O real vai se tecendo entre as dimensões iluminadas por cada paradigma e o que lhe escapa é rastreado pelo olhar rival, restando sempre, entretanto, um excesso -inacessível aos pensadores/atores analisados - a exigir a perícia do exegeta para dar-se à consciência. Perícia que terminará por expor suas próprias condições de possibilidade, trazendo o autor e sua circunstância para o centro do palco, e seu próprio paradigma para o foco da indagação. O que envolverá também a reflexão sobre a vida acadêmica e a institucionalização das ciências sociais, hoje, na periferia do capitalismo avançado, na América Latina, particularmente no Brasil. Esse exercício oferecerá o ambiente para uma preciosa análise da americanização da ciência política, que a desidrata, convertendo-a à metodolatria, em cujo âmbito as dinâmicas institucionais são estudadas isoladamente, isto é, dissociadas de sua dimensão sócio-histórica. Esse corte estimula uma especialização disciplinar e provoca todo um cortejo de conseqüências micropolíticas. Sobretudo, reifica o objeto de pesquisa e faz a disciplina percorrer um destino homólogo ao da própria institucionalidade política, cuja originalmente virtuosa autonomia tem se degradado em impermeabilidade à participação e à conexão efetivamente representativa com a sociedade. Da homologia logo se passa à identificação:essa empobrecida ciência da política não pode ver em seu objeto a incidência de um fenômeno e o tracejar de um movimento que também a afetam, (des)qualificam e alienam. Por isso, a conclusão é melancólica: adere ao status quo como sua ideologia.

Estaria enganado, entretanto, quem supusesse que, para o autore o ponto de vista expresso em sua obra -, real é o dado empírico em sua crueza bruta e independente, auto-suficiente em sua imanência ontológica, a-historicamente disponível, à espera de uma visada que o recolha. Nada mais distante da filosofia do conhecimento mobilizada por Linhagens do pensamento político brasileiro. Na obra, a realidade sociopolítica é esse embate, apanhado como objeto e produzido (intencio-
[2] Sublinhe-se a inadequação do emprego da categoria "paradigma", aqui aplicada apenas para rastrear sendas a serem exploradas com mais precisão, adiante. As razões da inadequação expõem-se mais à frente. 
nal e involuntariamente) pela ação humana multidimensional: embate entre, por um lado, as linhas de força do pensamento - cuja materialidade o situa no tempo e no espaço, submetendo-o à gravidade, à temperatura e à pressão dos jogos e dos confrontos de interesses e paixões, mais ou menos institucionalizados, e imprimindo a materialidade de sua marca ao conjunto dessas mesmas condições -; e, por outro lado, o universo das práticas, em sua fluidez e em suas cristalizações, em sua contingência e em sua necessidade, em suas excepcionalidades, rupturas, disfunções, e em suas leis, estruturas e regularidades - práticas que não deixam de ser atribuições de sentido e valor, e estabelecimento de relações, e que são também, portanto, pensamento, dando-lhe a forma de uma direção objetiva e subjetiva, no território da sociedade, mergulhada em sua historicidade.

Assim, o embate referido mostra-se, essencialmente, na tensão interna ao pensamento, que o constitui como prática sócio-histórica, e na tensão interna ao universo das práticas sociais, que as organiza como cadeias de sentido e direção, arquitetando a vertebração de uma hegemonia e um domínio de classe. Ambas as tensões se assimilam e se negam (idéia queé prática e prática queéidéia,em primeiro lugar de si mesma, na realização possível da consciência), reciprocamente, em uma dinâmica que talvez seja a da superação pela síntese - ou da "suprassunção". De tal maneira que a vitória política seja a prova (falsificável, por certo) do valor heurístico das idéias e de sua capacidade de dirigir (orientar a sociedade e organizá-la), produzindo o real-histórico (a sociedade sob certa organização) ao e por conhecê-lo (conhecendo-o por produzi-lo: eis o encontro entre Vico e Marx, nessa inesperada esquina do debate intelectual).

Por isso, aliás, idéias (sobretudo aquelas que tematizam política, poder e conflitos), política e conflito são elementos indissociáveis, numa sociedade de classes (moderna, pós-moderna e/ou tradicional), articulada por uma complexa rede de contradições que se sobredeterminam. E também por isso, uma história do pensamento político tem de ser, simultaneamente, uma análise política, a qual não se cumpre sem o exame de sua inscrição social. Observe-se que o inverso é igualmente verdadeiro, ou seja, o estudo da política não prescinde da interpretação de seu momento cognitivo-ideativo, ou, mais amplamente, cultural (incorporando-se aí, nessa categoria antropológica, o esforço de conferir inteligibilidade à experiência, via símbolos e conceitos, e a recriação/exegese de valores).

Portanto, pensar a política implica pensar o pensar a política, sendo esta última atividade, simultânea e irremediavelmente, uma intervenção nos processos sociais, voltada para, conscientemente ou não, buscar dar-lhes uma direção, na medida em que lhes dá um sentido (uma significação). A luta por hegemonia está inscrita na apa- 
rente letargia das esferas etéreas e abstratas. Aliás, essa aparência retrata a rotina sempre inconclusa de Sísifo: a inexorabilidade da relativa inconsciência de si dos conceitos, de seus portadores, dos agentes sociais que os encarnam - dirigindo-se por eles ou, inversamente, lhes apontando o sentido (a rigor, não faz diferença, o queé, aqui, a um tempo notável e crítico). Por isso, o real não engata, não adquire unidade sem a mediação da categoria totalidade - em sua ausência, como pensar a irredutível precariedade da consciência, no contexto em que o real só pode ser o real-pensado, mas aí não se encerra ou se esgota? -, a qual, por sua vez, traz consigo, inescapavelmente, a dialética. Eisnos de volta a Hegel e Marx, por um viés gramsciano.

Em benefício da clareza, retome-se o ponto nevrálgico: Gildo Marçal Brandão põe-se de tal modo frente ao objeto, define-o de tal forma que as idéias a serem redescritas e combinadas em modelos, conjuntos conceituais ou paradigmas, aparecem - graças ao condão de seu enfoque - encarnadas em processos históricos, materializando os programas que elas concebem e cultivam para cativar e dirigir, ou os programas cuja direção elas postulam e disputam.

$\mathrm{Na}$ arena de operações, defrontam-se os idealismos orgânico e constitucional: o primeiro, de extração autoritária, apostando no papel demiúrgico do Estado - ao qual caberia transformar em sociedade as costelas e as cinzas, o caos, o esgarçamento, a fragmentação -; o segundo, em forte dicção liberal, demonizando o Estado, cuja permanente intervenção sufocaria a energia criadora da sociedade. A nitidez do contraste só se sustenta no claro-escuro dos esquemas e, por isso mesmo, emerge com vigor apenas em alguns autores, algumas obras, em certos programas muito específicos de ação política. No desdobramento ordinário da vida política e em muitos autores, e em várias obras relevantes, imbricam-se pressupostos e análises, sobrepõem-se e entrecortam-se perspectivas e projetos de ação, compondo constelações bastante menos dicotômicas e extremadas, o que permite, inclusive, metamorfoses e hibridismos, e a conjugação de continuidade e ruptura. Nascem e procriam, assim, por exemplo, extensas famílias de liberais-autoritários, que acendem uma vela ao mercado e outra a Leviatã. Não é arbitrária, como se vê, a preferência do autor pelo vocabulário genealógico, em que heranças e afinidades compõem os seus puzzles familiares, sem banir as diferenças que lhe dão vida e sabor. Não é à toa que se fala em linhagens, em vez de paradigmas ou modelos, esses sendo mais próximos de concepções formalistas e estáticas, segundo as quais a lógica interna preside a formação do sentido e, até certo ponto, rege a comunicação com o exterior. Linhagens do pensamento politico brasileiro mergulha os personagens e seus mundos ideativos nas impurezas da vida e da história. Afunda a assepsia da razão na prodigiosa promiscuidade das relações, relativizando a própria distin- 
[3] E não só sobre política, porque uma tal segmentação entraria em contradição com a visão integradora e transdisciplinar que a obra postula e realiza. ção entre lógica interna e eventos externos - aquela admitindo e assimilando a contingência desses últimos eestes encenando a trama dos conceitos (ou seja, a "lógica" do sistema) no palco da história.

$\mathrm{Na}$ cartografia de Linhagens, que passa em revista a maior parte dos principais estudos e pontos de vista sobre a política ${ }^{3}$, no Brasil, há espaço para a reflexão que amadurece à esquerda dos idealismos orgânico e constitucional - e de suas múltiplas combinações ou de suas surpreendentes reaparições em pensamentos, palavras e obras. Posição singular é ocupada pelo desenvolvimentismo, que conjuga componentes de um marxismo à brasileira - por seu reconhecimento da estrutura que, ordenando as classes sociais, se rebate na política - a elementos do viés organicista - por sua valorização do Estado na formação da sociedade brasileira - e também a elementos liberais, por seu rechaço do autoritarismo e da verticalidade organicista-corporativa. Situando o grupo intelectual-político com o qual se identifica e, assim, inscrevendo-se no quadro que desenha - revelando, ao mesmo tempo, por que ele é cartografado desse modo -, o autor postula um novo desenvolvimentismo, colado a uma perspectiva que focaliza e destaca a centralidade da democratização, como processo continuado, aberto e contraditório, campo de luta e disputa hegemônica, tanto no plano conceitual quanto nos níveis valorativo-ideológico e prático-político.

Soberbo, na obra de Gildo Marçal Brandão, não é propriamente a demonstração da pregnância de certo arranjo ordenador do campo ideativo, no pensaro país, a sociedade, sua história, a nação, o Estado e a política, mas esse apanhar em ato - feito história — o novelo das idéias.

Finalmente, procurando ser fiel ao rigor da obra examinada, cumpre registrar uma falta - afinal, como o próprio autor insistiria, não há pensamento plenamente consciente de sie de seu objeto, sem fissuras, poros e limites. Não se trata, exatamente, de algo que não está na obra eque deveria estar, mas de uma ausência presente na obra, ou seja, evocada, tacitamente, por seu movimento reflexivo.Ao evocar as interpretações do Brasil e mencionar a escassa teorização no país, e ao fazer tudo isso enquanto sustenta a necessidade de evitar o paroquialismo das disciplinas, no campo das ciências humanas, é a obra mesma, Linhagens do pensamento político brasileiro, que suscita uma implicação não explicitada, não trabalhada, sequer reconhecida. Se teoria sobre o social é relevante para a ciência política, a qual não se reduz à análise institucional ou ao estudo do Estado, como sustentar que a teorização tem sido escassa no Brasil, se temos vivido, nas últimas duas décadas, o que poderia ser definido com uma das mais prolíficas e ricas experiências de teorização sobre o social? Refiro-me ao que tem ocorrido no campo da antropologia. Nenhuma genealogia sobre a reflexão social estará completa sem a referência à obra de Eduardo Viveiros de 
Castro e seus parceiros de pesquisa etnológica. Mas a que preço far-seia essa inclusão? O ingresso da etnologia no quadro produziria que efeitos? O novo desenvolvimentismo conectado à democratização como processo sofreria alguma inflexão, do ponto de vista teórico? $\mathrm{O}$ próprio tratamento conferido às teorias sobre o Brasil seria submetido a algum novo desafio? Os fundamentos filosóficos mobilizados em Linhagens sofreriam algum sério questionamento? Alguns personagens e obras não contemplados alcançariam inusitado protagonismo?

Eis aí a síntese de uma nova agenda político-intelectual que talvez merecesse um lugar de destaque na mesa de trabalho dos que se identificam com os pontos de vista de Linhagens. A excelência de uma obra está também em seu caráter interminável, ou melhor — para concluir com uma boutade -, está também na "impaciência conceitual" que suscita em todos os atores que habitam o universo interpelado.

LUIZ EDUARDO SOARES é, professor da UERJ e da ESMP, é Secretário Municipal de Valorização da Vida e Prevenção da Violência de Nova Iguaçu. 